08,09

\title{
Влияние неконтролируемых примесей на спектр поглощения лазерного кристалла $\mathrm{NaGd}\left(\mathrm{WO}_{4}\right)_{2}$
}

\author{
(C) М.П. Зыкова ${ }^{1}$, К.А. Субботин ${ }^{1,2}$, С.К. Павлов ${ }^{1}$, Д.А. Лис ${ }^{2}$, Е. Чернова ${ }^{1}$, \\ Е.В. Жариков ${ }^{2}$, И.Х. Аветисов ${ }^{1, \uparrow}$ \\ ${ }^{1}$ Российский химико-технологический университет им. Д.И. Менделеева, \\ Москва, Россия \\ ${ }^{2}$ Институт общей фризики им. А.М. Прохорова РАН, \\ Москва, Россия \\ ฯE-mail: igor_avetisov@mail.ru
}

Поступила в Редакцию 16 июля 2019 г.

В окончательной редакции 16 июля 2019 г.

Принята к публикации 25 июля 2019 г.

\begin{abstract}
Методом Чохральского выращены три монокристалла $\mathrm{NaGd}\left(\mathrm{WO}_{4}\right)_{2}$ с использованием шихты с различной химической чистотой. Выполнен анализ примесного состава выращенных кристаллов методом массспектрометрии с индуктивно связанной плазмой. Измерены спектры оптического поглощения кристаллов и проанализировано влияние неконтролируемых примесей на оптические свойства кристаллов и их окраску. Показано, что зеленая окраска, которая иногда встречается в кристаллах $\mathrm{NaGd}\left(\mathrm{WO}_{4}\right)_{2}$ обусловлена наличием неконтролируемых примесей $d$-элементов, из которых наиболее значимо влияет примесь хрома.
\end{abstract}

Ключевые слова: примесная чистота, вольфрамат цинка, иттербий, монокристаллы, центры окраски, оптическое поглощение.

DOI: $10.21883 /$ FTT.2019.12.48606.61ks

\section{1. Введение}

Монокристалл вольфрамата натрия-гадолиния $\mathrm{NaGd}$ $\left(\mathrm{WO}_{4}\right)_{2}(\mathrm{NGW})$ является одной из перспективных лазерных матриц для легирования редкоземельными ионами (РЗИ). Лазеры на кристаллах NGW, легированных различными РЗИ, эффективно работают как в режиме синхронизации мод, так и в режиме плавной перестройки длины волны излучения в достаточно широких диапазонах [1-4]. Структура данного кристалла является производной от структуры шеелита $\mathrm{CaWO}_{4}$ и состоит из $\left[\mathrm{WO}_{4}\right]^{2-}$ - тетраэдров, при этом катионы $\mathrm{Na}^{+}$ и $\mathrm{Gd}^{3+}$, замещающие $\mathrm{Ca}^{2+}$, находятся внутри сильно искаженного восьмикратного кислородного окружения. Кристаллы NGW, легированные РЗИ, имеют пространственные группы $I 4_{1} / a, I / 4, I 4 / m$ или $I 4$, с параметрами элементарной ячейки $a \sim 5.22 \AA, c \sim 11.35 \AA$, в зависимости от конкретной легирующей примеси и ее концентрации [3,5-9]. Данные кристаллы могут быть легко получены методом Чохральского, при этом все РЗИ обладают хорошей твердофазной растворимостью в кристалле $[1,3,4,6,7,9]$.

Будучи структурно разупорядоченными, кристаллы NGW обеспечивают широкие оптические полосы поглощения и люминесценции РЗИ. Более того, сильные искажения локального окружения легирующей примеси приводят к существенному смягчению запрета Лапорта на электродипольные $f-f$-переходы в РЗИ [10]. Это приводит к достаточно высоким вероятностям и удельным интенсивностям излучения на спектральных переходах РЗИ $[3,4,7,10-12]$.
Одной из проблем этих кристаллов, впервые обсуждавшейся в работе [6], является время от времени возникающая дополнительная (не связанная с РЗИ-легированием) зеленая окраска кристаллов. Эта окраска не исчезает в процессе отжига кристаллов. Более того, предполагается, что интенсивность зеленой окраски кристаллов NGW не зависит от „внешних“ условий роста (атмосферы роста, материала тигеля, скорости вытягивания и т.п.). Между тем, эта дополнительная окраска существенно ухудшает генерационные характеристики кристаллов, вплоть до полного ее подавления. В настоящей работе мы попытались выяснить причину зеленой окраски кристаллов NGW путем анализа влияния неконтролируемых примесей на оптические свойства кристаллов.

\section{2. Экспериментальная часть}

Кристаллы NGW были выращены методом Чохральского на ростовой установке „Кристалл- $2^{“}$ из платинородиевого тигля на воздухе. В качестве затравки использовали монокристаллический брусок NGW, вырезанный перпендикулярно главной кристаллографической оси 4-го порядка. Скорость вытягивания составляла $1 \mathrm{~mm} / \mathrm{h}$, скорость вращения составляла $6 \mathrm{rpm}$. После роста кристаллы охлаждали до комнатной температуры со скоростью $10 \mathrm{~K} / \mathrm{h}$, чтобы избежать растрескивания.

Для подготовки шихты был использован оксид вольфрама (VI) из двух разных партий производства ООО „Ланкхит“, Россия. Партия № $1-\mathrm{WO}_{3}$ имела заявлен- 

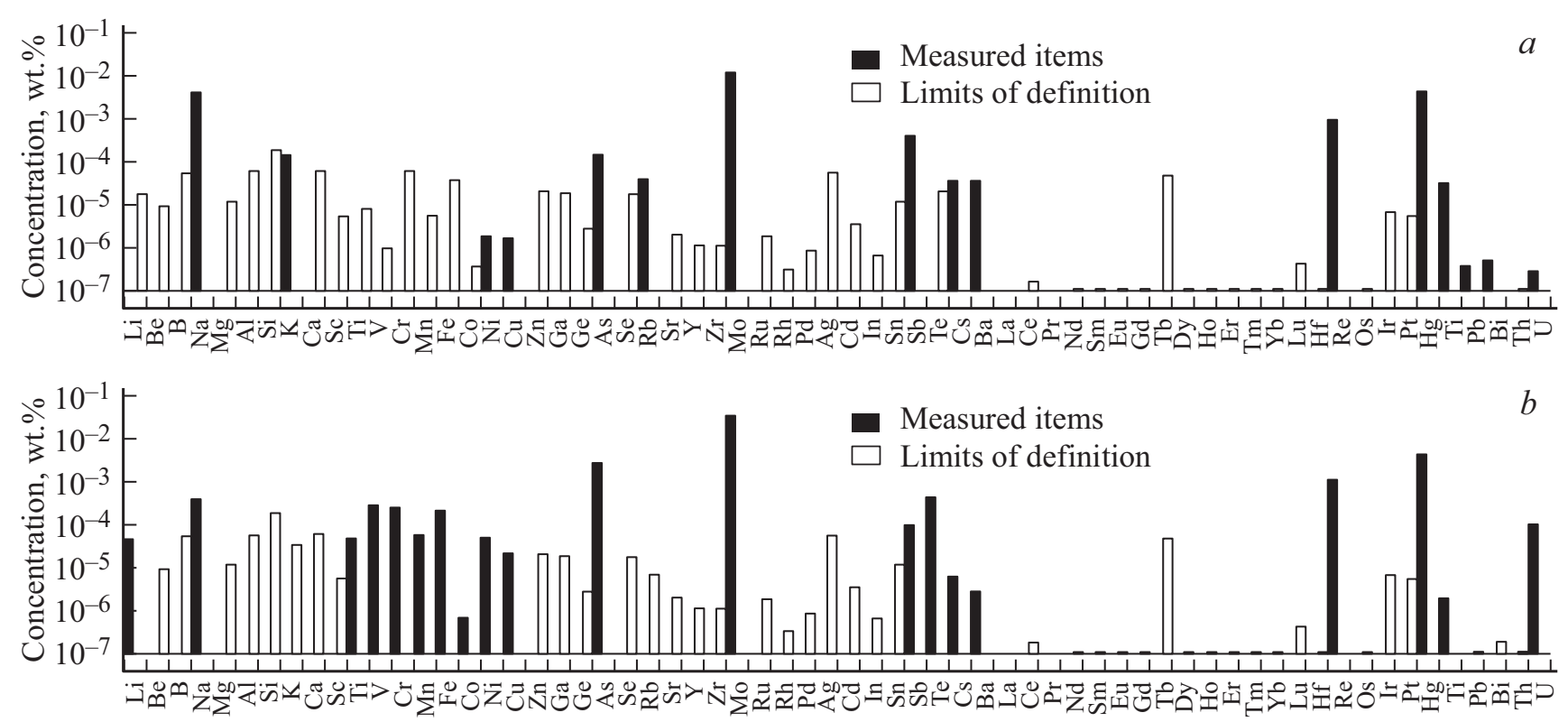

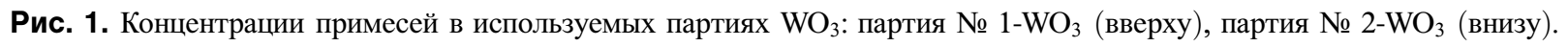

ную производителем чистоту $5 \mathrm{~N}$ по металлическим примесям; партия № 2- $\mathrm{WO}_{3}-4 \mathrm{~N}$. Другими исходными веществами были: $\mathrm{Na}_{2} \mathrm{CO}_{3}$ (Х.Ч.) и $\mathrm{Gd}_{2} \mathrm{O}_{3}$ (GdO-G, ОСТ 48-200-81, ОС.Ч.). Исходные реактивы были взвешены на аналитических весах Sartorius, тщательно перемешаны, и полученные смеси перед загрузкой в ростовой тигель прокаливались при температуре $700^{\circ} \mathrm{C}$ в течение $4 \mathrm{~h}$ в муфельной печи для протекания твердофазного синтеза.

Примесные составы как $\mathrm{WO}_{3}$ (обеих партий), так и выращенных кристаллов определяли с помощью масс-спектрометрии с индуктивно связанной плазмой (ICP-MS, NexION 300D. Perkin-Elmer, CША). Кроме того, состав кристаллов измеряли с помощью искровой масс-спектрометрии (SMS) на масс-спектрометре JMS-01-BM2 (JEOL, Япония). Спектры оптического поглощения измеряли на спектрофотометре Cary 5000 (Varian, Франция) в диапазоне длин волн 300-2000 nm.

\section{3. Результаты и обсуждение}

Анализ примесной чистоты двух партий оксида вольфрама (VI) представлен на рис. 1 (здесь и далее выявленные элементы с концентрациями, превышающими пределы определения с помощью ICP MS, представлены сплошными черными прямоугольниками; в случае остальных элементов, концентрации которых в образцах ниже пределов определения, представлены их пределы определения в виде пустых прямоугольников). Согласно результатам анализа основным отличием между используемыми партиями $\mathrm{WO}_{3}$ является наличие $3 \mathrm{~d}$-элементов во второй партии $(\mathrm{Ti}, \mathrm{V}, \mathrm{Cr}, \mathrm{Mn}, \mathrm{Fe}, \mathrm{Ni}, \mathrm{Cu})$ в концентрациях на уровне $10^{-4}-10^{-5} \mathrm{wt} \%$. Известно, что ионы 3d-элеметов, обычно характеризующиеся электронно- колебательными спектральными переходами, могут давать широкие интенсивные полосы в спектрах поглощения конденсированных сред, в которых они локализованы. Партия № $1-\mathrm{WO}_{3}$ была гораздо чище по этим примесям, за исключение $\mathrm{Ni}$ и $\mathrm{Cu}$.

Что касается других элементов в партиях $\mathrm{WO}_{3}$ (щелочные ионы, $\mathrm{Mo}, \mathrm{As}, \mathrm{Re}, \mathrm{Hg}, \mathrm{Tl}$ и др.), то их концентрации оказались относительно большими и сопоставимыми для обеих партий. Однако, известно, что эти примеси не участвуют в образовании дополнительного оптического поглощения в кристаллах, по крайней мере, при концентрациях $10^{-3}-10^{-4} \mathrm{wt} \%$.

Партия № $1 \mathrm{WO}_{3}$ была использована для выращивания монокристаллов № 1-NGW и № 2-NGW. Кристалл

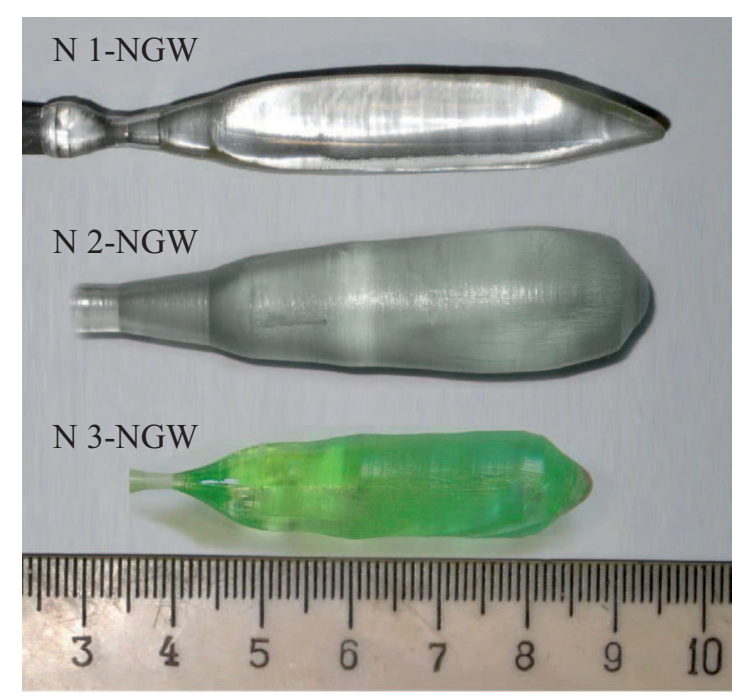

Рис. 2. Фотографии выращенных кристаллов $\mathrm{NaGd}\left(\mathrm{WO}_{4}\right)_{2}$ № 1-NGW, № 2-NGW, № 3-NGW. 

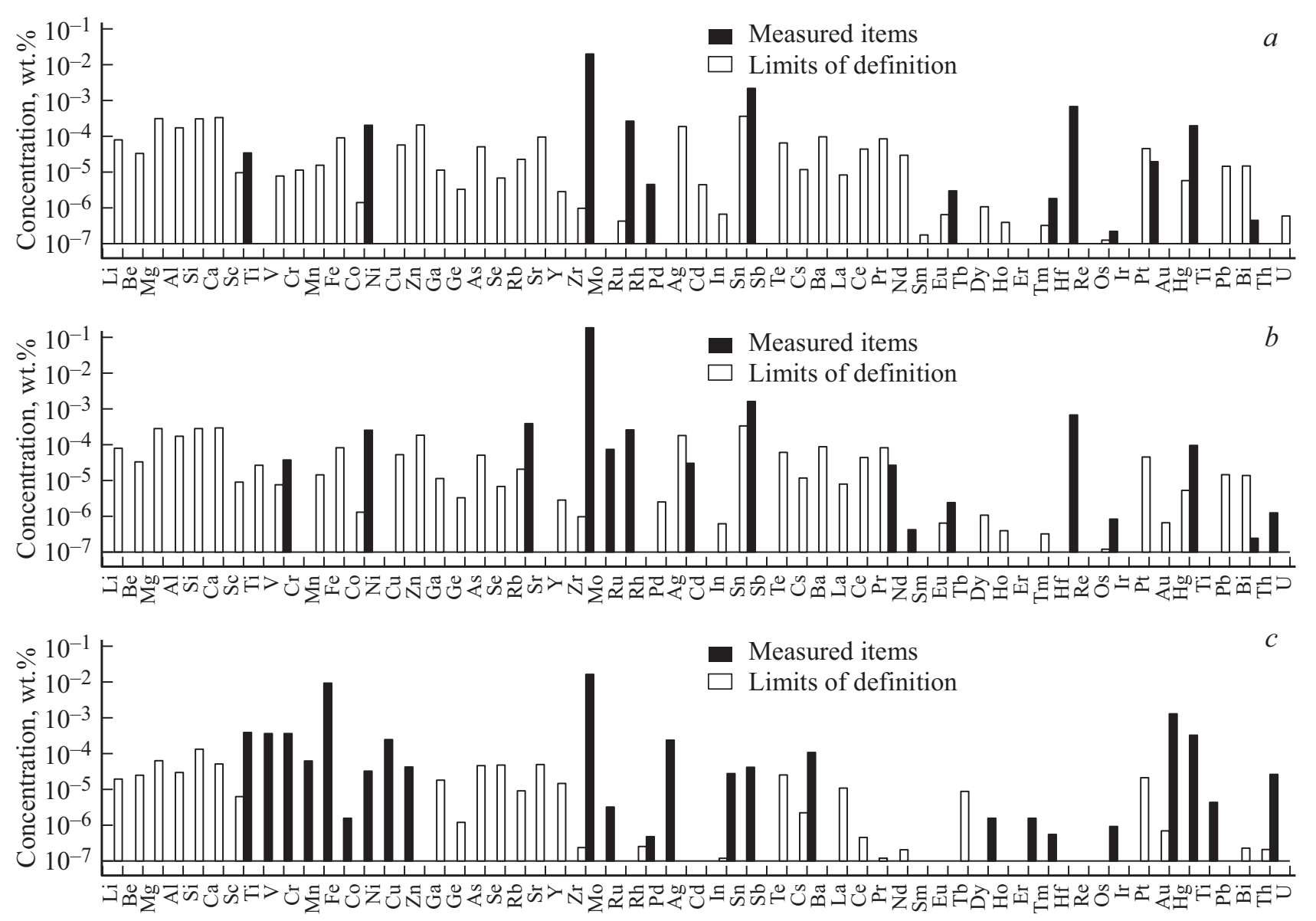

Рис. 3. Концентрации примесей в выращенных кристаллах $\mathrm{NaGd}\left(\mathrm{WO}_{4}\right)_{2}$ : кристалл № 1-NGW (a); кристалл № 2-NGW (b); кристалл № 3-NGW (c).

№ 1-NGW оказался бесцветным, без видимой окраски. Кристалл № 2-NGW имел бледно-зеленую окраску. Кристалл № 3-NGW был выращен с использованием партии № 2- $\mathrm{WO}_{3}$ и имел ярко-зеленую окраску (рис. 2).

Примесные составы кристаллов № 1-NGW и № 2-NGW очень похожи (рис. 3). Источником ряда примесей (Mo, Re, Tl и др.), является, по-видимому, $\mathrm{WO}_{3}$. Источником некоторые других примесей (прежде всего, РЗИ), очевидно, является $\mathrm{Gd}_{2} \mathrm{O}_{3}$, тогда как родий, по-видимому, был захвачен расплавом из тигля. Основным и очевидным отличием примесных составов кристаллов № 1-NGW № 2-NGW является наличие хрома во втором из них в концентрациях, превышающих пределы определения. Основное и принципиальное отличие примесного состава кристалла № 3-NGW от такового в кристаллах № 1-NGW и № 2-NGW заключается в наличии всех 3d-ионов ( $\mathrm{Ti}, \mathrm{V}, \mathrm{Cr}, \mathrm{Mn}, \mathrm{Fe}$, $\mathrm{Ni}, \mathrm{Cu}$ ), которые содержатся в партии № 3- $\mathrm{WO}_{3}$. Единственным очевидным исключением является железо: оно присутствует в кристалле № 3-NGW в концентрации $10^{-2} \mathrm{wt} \%$. Аналогичный результат был получен с помощью SMS анализа. Такое большое количество железа не могло попасть в кристаллическую фазу из исходных $\mathrm{WO}_{3}$ или $\mathrm{Gd}_{2} \mathrm{O}_{3}$, и весьма сомнительно, что оно могло попасть в кристалл из технологического оборудования во время получения кристалла. Вероятно, основная часть железа попала в кристалл из $\mathrm{Na}_{2} \mathrm{CO}_{3}$, который был не таким чистым, как нам хотелось бы.

Из анализа полученных нами результатов и литературных данных следует, что примесь железа, по-видимому, не является наиболее важным окрашивающим агентом в исследованных кристаллах NGW.

Действительно, самой сильной полосой оптического поглощения в кристаллах, вызывающей зеленую окраску, является полоса в диапазоне 600-800 nm (рис. 4). Интенсивность этой полосы составляет около $0.07 \mathrm{~cm}^{-1}$ в кристалле № 2-NGW и около $0.3 \mathrm{~cm}^{-1}$, т.е. в 5 раз больше - в кристалле № 3-NGW. Разница же в концентрации железа между кристаллами № 2-NGW и № 3-NGW, обнаруженная как с помощью ICP-MS, так и с помощью SMS-анализа, составляет, по меньшей мере, два порядка. Кроме того, полоса поглощения в диапазоне $600-800 \mathrm{~nm}$ - не самая типичная для железа. Известно, что самая сильная полоса поглощения ионов $\mathrm{Fe}^{2+}$ в оксидных кристаллах находится в районе $1 \mu \mathrm{m}[13,14]$, тогда как ионы $\mathrm{Fe}^{3+}$ имеют полосу поглощения с максимумом в ультрафиолетовой области с очень широким длинноволновым склоном, простираю- 


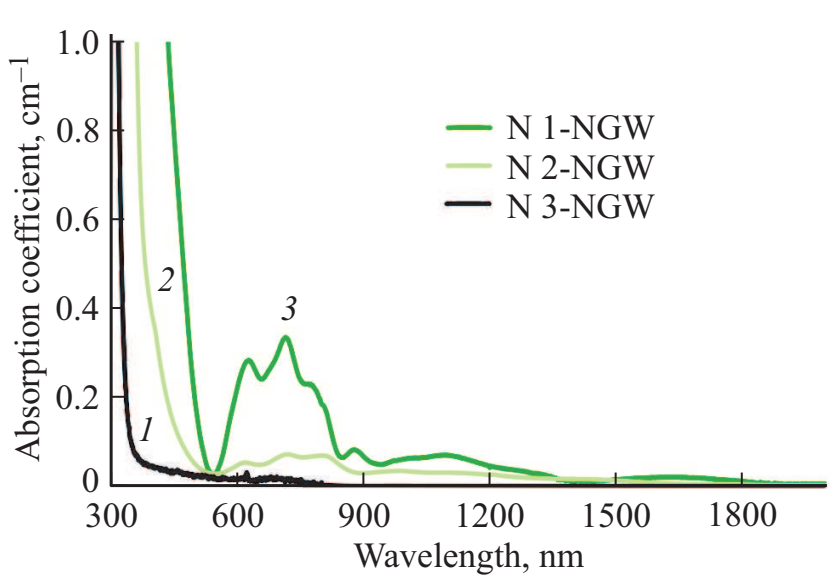

Рис. 4. Спектры неполяризованного оптического поглощения монокристаллов NGW при $300 \mathrm{~K}$.

щимся до 700-800 nm [14]. Возможно, небольшой пик в районе $900 \mathrm{~nm}$, наблюдаемый в спектре поглощения кристалла № 3-NGW, является поглощением иона $\mathrm{Fe}^{2+}$.

Мы полагаем, что наиболее важной поглощающей примесью в исследованных кристаллах, обуславливающей данную окраску, является хром в разных степенях окисления. Действительно, содержание хрома в кристаллах № 2-NGW и № 3-NGW составляет $3.8 \cdot 10^{-5}$ и $3.3 \cdot 10^{-4} \mathrm{wt} \%$ соответственно. Тогда как содержание этой примеси в кристалле № 1-NGW ниже предела определения $\left(1.1 \cdot 10^{-5} \mathrm{wt} \%\right)$. Эти соотношения концентраций хрома близки к соотношениям интенсивностей полосы оптического поглощения в районе $600-800 \mathrm{~nm}$ в исследованных кристаллах.

Хром в кристаллах NGW может находиться в различных степенях окисления: ионы $\mathrm{Cr}^{4+}$ и $\mathrm{Cr}^{6+}$ могут замещать ионы $\mathrm{W}^{6+}$ в тетраэдрических позициях, а ион $\mathrm{Cr}^{2+}$, может занимать кальциевые позиции шеелитовой структуры (замещать ионы $\mathrm{Na}^{+}, \mathrm{Gd}^{3+}$ ). Тетраэдрически координированный четырехвалентный хром имеет две основные широкие полосы поглощения: в районе 600-800 nm (в зависимости от силы кристаллического поля), обусловленную электронно-колебательным переходом ${ }^{3} A_{2} \rightarrow{ }^{3} T_{1}$, и в районе $900-1100 \mathrm{~nm}$ (опять же, в зависимости от конкретной силы кристаллического поля), обусловленную электронно-колебательным переходом ${ }^{3} A_{2} \rightarrow{ }^{3} T_{2}$ [13]. Первая полоса на порядок интенсивнее второй, и она, как правило, расщеплена на три орбитальных компонента низкосимметричным кристаллическим полем.

Для шестивалентного хрома характерна одна чрезвычайно интенсивная широкая оптическая полоса поглощения в области $350-370 \mathrm{~nm}$ (в зависимости от силы кристаллического поля конкретной матрицы), обусловленная переходом с переносом заряда [15]. Двухвалентный хром имеет две наиболее сильные широкие полосы поглощения в районе $800 \mathrm{~nm}$ и около $1700-2000 \mathrm{~nm}$. Первая полоса связана с переходом ${ }^{5} E \rightarrow{ }^{5} T_{2}$ [13], другая - по мнению [13] связана с переходом между различными ян-теллеровскими компонентами уровня ${ }^{5} E$, а в работе [16] эту полосу связывают с переходом ${ }^{5} E \rightarrow{ }^{3} T_{1}$. Все указанные полосы можно наблюдать на спектрах поглощения исследованных кристаллов.

Присутствие иона $\mathrm{Cr}^{3+}$, имеющего характерные широкие полосы поглощения с максимумами в районе $400-500 \mathrm{~nm}$ и при $600-700 \mathrm{~nm}$ (в зависимости от силы кристаллического поля конкретной матрицы) [13], также нельзя исключить.

\section{4. Заключение}

Правомерность сделанного в статье вывода о том, что формирование зеленой окраски в кристаллах $\mathrm{NaGd}\left(\mathrm{WO}_{4}\right)_{2}$ обуславливается наличием ионов хрома в различных степенях окисления, может быть подтверждена исследованиями люминесцентных характеристик, включая измерения кинетики затухания люминесценции, a также измерениями ЭПР. Эти исследования будут выполнены на данных кристаллах в ближайшее время. Все остальные примеси, обнаруженные в кристаллах, играют, вероятно, незначительную роль в спектрах поглощения исследованных кристаллов NGW.

\section{Финансирование работы}

Работа выполнена при финансовой поддержке Министерства науки и высшего образования России по проекту RFMEFI57418X0186.

\section{Конфликт интересов}

Авторы заявляют, что у них нет конфликта интересов.

\section{Список литературы}

[1] E.V. Zharikov, D.A. Lis, A.V. Popov, K.A. Subbotin, S.N. Ushakov, A.V. Shestakov. I. Razdobreev. Quantum Electron. 36, 515 (2006).

[2] J.M. Cano-Torres, M.D. Serrano, C. Zaldo, M. Rico, X. Mateos, Junhai Liu, U. Griebner, V. Petrov. J. Opt. Soc. Am. B 23, 2494 (2006).

[3] J.M. Cano-Torres, M. Rico, X. Han, M.D. Serrano, C. Cascales, C. Zaldo, V. Petrov, U. Griebner, X. Mateos, P. Koopmann, C. Krankel. Phys. Rev. B 84, 174207 (2011).

[4] E.V. Zharikov, C. Zaldo. F. Diaz. MRS BULleTIN 34, 271 (2009).

[5] Е.В. Жариков, Г.М. Кузьмичева, Д.А. Лис, Ю.М. Папин, В.Б. Рыбаков, В.А. Смирнов, К.А. Субботин. Неорган. материалы 39, 200 (2003).

[6] G.M. Kuz'micheva, D.A. Lis, K.A. Subbotin, V.B. Rybakov, E.V. Zharikov. J. Cryst. Growth 275, e1835 (2005).

[7] F.A. Bolschikov, G.M. Kuz'micheva, D.A. Lis, Yu.M. Papin, A.V. Popov, P.A. Ryabochkina, V.B. Rybakov, V.G. Senin, V.A. Smirnov, K.A. Subbotin, Yu.K. Voron'ko, V.V. Voronov, E.V. Zharikov. J. Cryst. Growth 311, 4171 (2009). 
[8] Г.М. Кузьмичева, В.Б. Рыбаков, В.Л. Панютин, Е.В. Жариков, К.А. Субботин. Журн. неорган. химии 55, 1534 (2010).

[9] J. Fan, H. Zhang, J. Wang, Z. Ling, H. Xia, X. Chen, Y. Yu, Q. Lu, M. Jiang. J. Phys. D 39, 1034 (2006).

[10] P.A. Ryabochkina, S.A. Antoshkina, S.A. Klimin, D.A. Lis, K.A. Subbotin, S.N. Ushakov, E.V Zharikov. J. Lumin. 138, 32 (2013).

[11] Ю.К. Воронько, Е.В. Жариков, Д.А. Лис, А.А. Соболь, К.А. Субботин, С.Н. Ушаков, В.Е. Шукшин, С. Дрёге. Неорган. материалы 39, 1509 (2003).

[12] A. Garcia-Cortes, C. Zaldo, C. Cascales. Opt. Mater. 31, 1096 (2009).

[13] S. Kück. Appl. Phys. B 72, 515 (2001).

[14] M.N. Taran, K. Langer. Phys. Chem. Miner. 28, 199 (2001).

[15] C. Koepke, K. Wishniewski, M. Grinberg. J. Alloys Comp. 341, 19 (2002).

[16] Y. Yamaguchi, K. Yamagishi, Y. Nobe. J. Cryst. Growth 128, 996 (1993).

Редактор Д.В. Жуманов 